\title{
Urban Land Use Planning Trend and Sustainable Challenges in Socio-Economic Development
}

\author{
MUHAMMAD YOUSIF MANGI* $\dagger$, IMTIAZ AHMED CHANDIO*, MIR AFTAB HUSSAIN TALPUR*, \\ AND FAHAD AHMED SHAIKH* \\ RECEIVED ON 22.02.2017 ACCEPTED ON 13.11.2017 \\ ABSTRACT
}

\begin{abstract}
Land use planning is a technical approach for developing and managing the land into various public interests to endorse sustainable socio-economic development. This paper focuses on socio-economic problems by improper allocations of urban land uses particularly in vertical development (High rise buildings). Taluka Qasimabad Town was selected as a case study to observe the existing urban land use trends. Spatial and Quantitative data were collected through detailed land use survey and formal interviews. The ArcGIS and SPSS (Statistical Package for Social Science) online software were used to analyze spatial and quantitative data. LRM (Linear Regression Model) was used for predicting urban land use change particularly in vertical development by the year 2050. In this context, yearly code and land use change variables were applied in LRM to predict land use change since 2007. The results were found that rapid change in land uses occurred in the study area, by which inhabitants are facing problems like privacy, insecurity, property devaluation, and orientation nearby their accommodations. This research can lead to suggest several ways to improve and enhance urban land use planning approaches for betterment of urban communities.
\end{abstract}

Key Words: Urbanization, Urban Land Use Planning, Linear Regression Model.

\section{INTRODUCTION}

U rbanization is one of the serious global issues. Urbanization is considered as a worldwide trend that has increased mainly in the last century [1]. At present, urban areas accommodate half of the world's population, and this percentage may continue to rise [2]. Pakistan is also confronting with rapid growth of urbanization. The urban population of Pakistan was $32.5 \%$ in 1998 , which is expected to rise by $50 \%$ up till the year 2030 [3]. Urbanization and rapid spatial development in urban premises without considering existing cities' development requirements are all dominated on urban land uses in Pakistan [4]. Thus, effective and efficient land use planning and management mainly for vertical development is not well implemented. It results in disorganized situation of land uses in the cities [5]. In this paper, land use planning approach is taken under observation. Land use planning 
is a basic process for planning, organizing and managing mechanism to control the existing or new land uses assigned for various purposes by the cooperation of building and development control authorities, local district government departments and local people [6]. It is also a technique to overcome improper urban land uses through collaborative efforts [7]. Worldwide socio-economic considerations are completely interconnected and recognized with land use planning. In urban context, socioeconomic development and land use planning is not the selection but a necessity for today's world population, when dwellers needs are fulfilled by the cities. Thus, urban areas must be socially unbiased, economically favorable and environmentally sustainable, when cities are considered as a future for humanities [8]. The purpose of this study is to bring in the urban land use planning mechanism in Pakistan. This concept can be introduced to enhance and promote socio-economic and physical development and can adopt systematic land use planning for betterment of urban life. Therefore, land use planning can lead to tackle associated problems through regulating by-laws and recommend suitable solutions for vertical urban development in a sustainable way [9].

\section{STUDY AREA}

Taluka Qasimabad, the western part of the city of Hyderabad Sindh, Pakistan is selected as a case to investigate the various actors' perception of urban land use planning trends. It is located on $25.24^{\circ} \mathrm{N}$ latitude, $68.20^{\circ} \mathrm{E}$ longitude coordinates. The total area of site is about 49,800 acres, which is consisted on both developed and under development area. It is also administratively subdivided into four Union Councils, and the city of Qasimabad is the headquarters (Fig. 1).

\section{METHODS}

The increasing demand of socio-economic research work created a necessity for an efficient method of elaborating the sample size to represent a given demographic condition in the study area. In this study, a sample of 385 questionnaires was selected with respect to size of
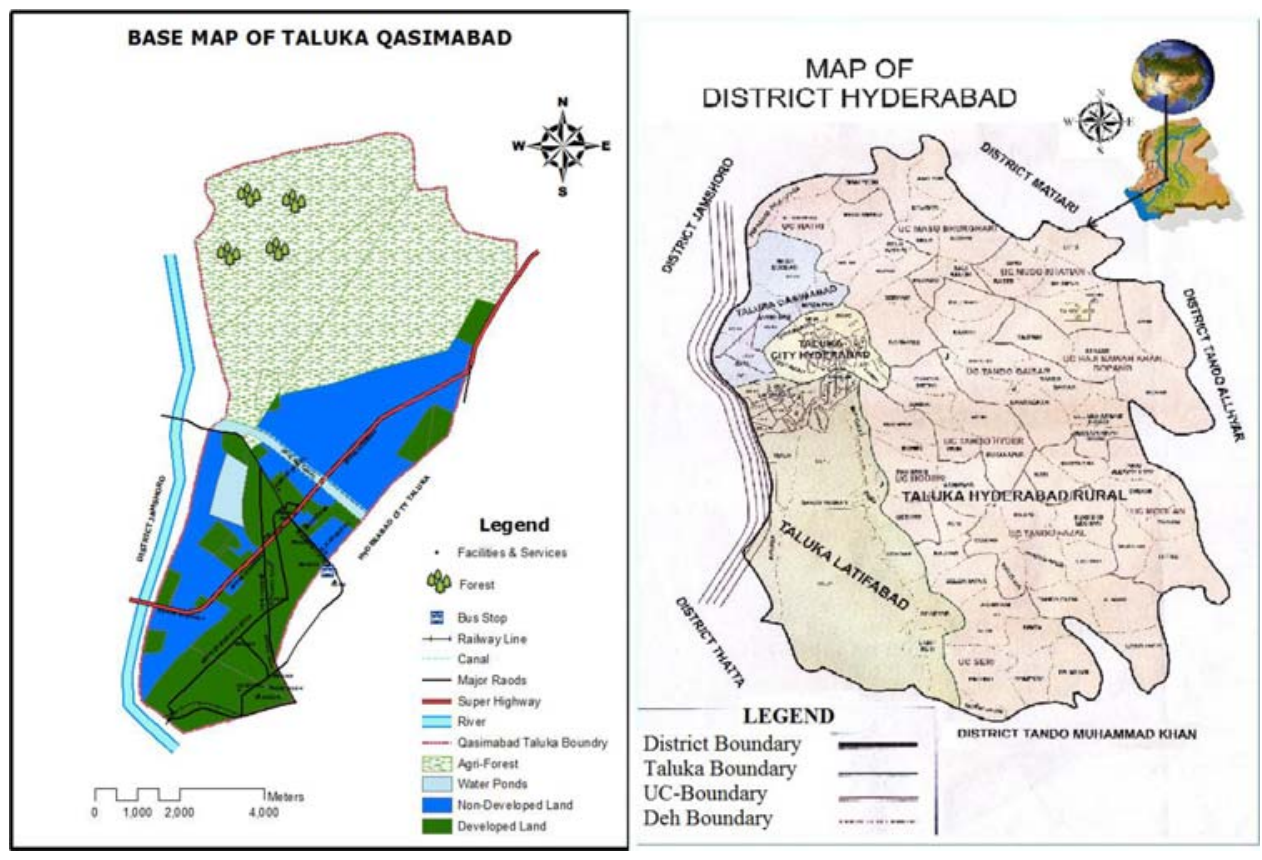

FIG. 1. LOCATION OF TALUKA QASIMABAD

Mehran University Research Journal of Engineering \& Technology, Volume 37, No. 2, April, 2018 [p-ISSN: 0254-7821, e-ISSN: 2413-7219] 
population [10]. Moreover; the detailed questionnaires were randomly filled from local inhabitants mainly in three clusters i.e. East (Alamdar, Citizen and Gulistan-e-Sajjad), West (Qasimabad Phase I \& II) and Central (Naseem Nagar and Wadhu Wah) Qasimabad Town, Hyderabad.

Land use change prediction model was applied to examine future provision of urban land uses improperly. Land use change model was performed in SPSS through linear regression statisticical technique [11,12]. For land use change model, the relationship between two variables was measured such as; the yearly code and land use change mainly in vertical development to identify increasing improper land conversion regularly. This statistical model is described as follows:

(i) LUC = rate of growth + constant factor (Yearly Code)

\section{Using following formulas for regression} parameters: rate of growth and constant factor.
Rateo f Growth (a) $=\frac{n \sum_{x_{i}, y_{i}} \sum_{x_{i} Y_{i}}}{n \sum_{x_{i}}^{2}-\left(\sum_{x_{i}}\right)}$

and

Constant Factor $(b)=\bar{y}-a \ddot{x}$

where $\mathrm{x}$ is yearly code $\mathrm{y}$ is LUC

(iii) using Equations (2-3) and data in Table 1 we have; $\mathrm{a}=0.366$ and $\mathrm{b}=0.520$

So, by putting rate of growth (a) and constant factor (b) values in Equation (1), we get the results according to yearly code;

(iv)

$$
\mathrm{LUC}=0.366 \mathrm{YC}+0.520
$$

where, $\mathrm{YC}=$ $,-1,0,1, \ldots$ $(-1 \mathrm{YC}=2006$ and $+1 \mathrm{YC}=2008)$ and $\mathrm{YC}=0$ corresponds to 2007 as shown in Table 1.

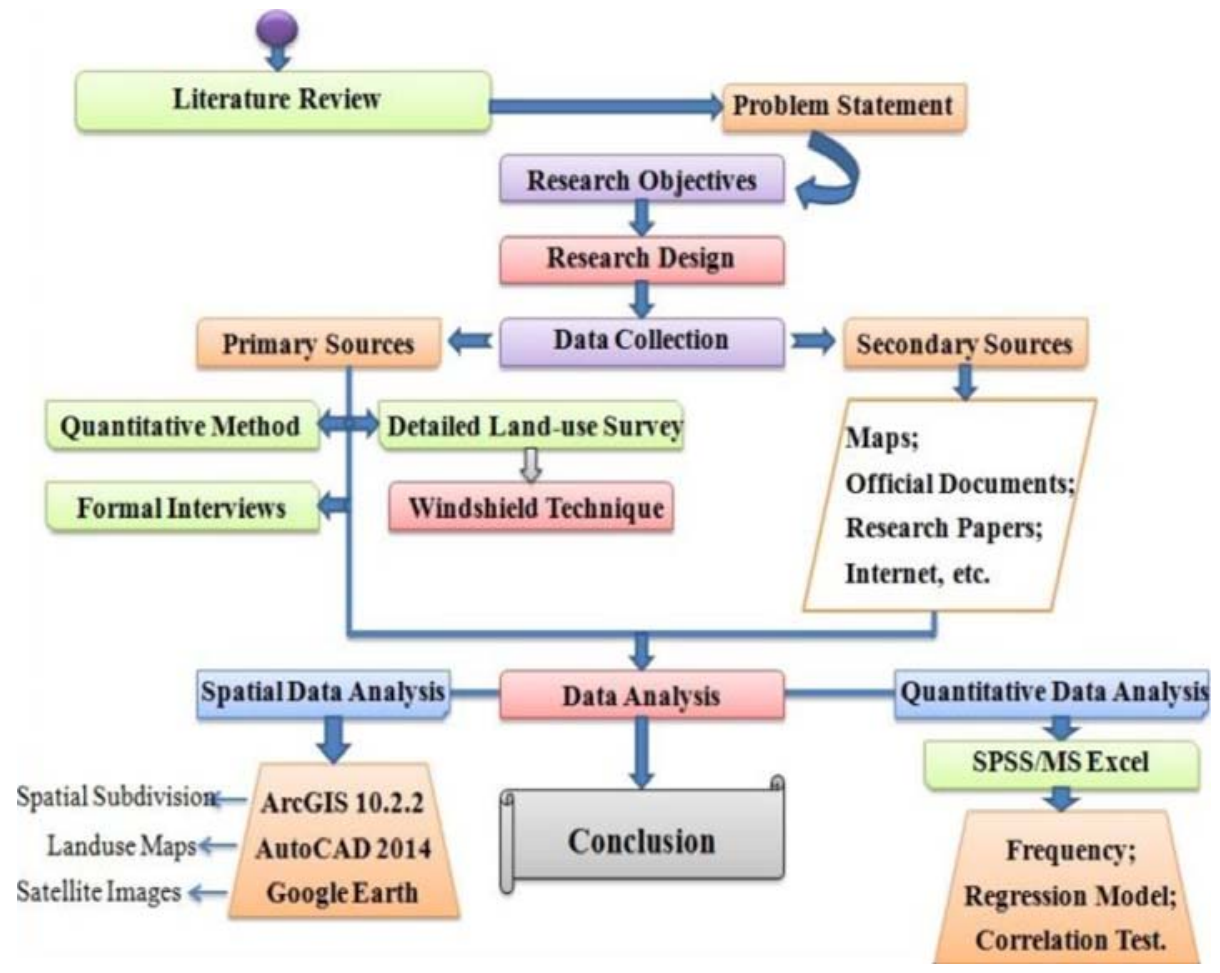

FIG. 2. RESEARCH METHODOLOGY

Mehran University Research Journal of Engineering \& Technology, Volume 37, No. 2, April, 2018 [p-ISSN: 0254-7821, e-ISSN: 2413-7219] 
While LUC (y) is counted as a dependent variable and yearly code (x) is notified as an independent variable. Meanwhile, rate of growth of $y$ (or intercept of regression line) is represented with "a" and the constant factor represented with "b" indicates a slope of the line as shown in Fig. 3.

\section{RESULTS AND DISCUSSION}

As shown in Table 1 two different variables were taken to predict improper land use change in vertical development. The data was predicted focussing land use changes by the year 2050.

Table 1 shows different parameters of yearly code and land use change variables. For calculation of yearly code and land use change variables, a linear regression model was undertaken to find past, present and future of land use trends. Nevertheless, this study model can be significant for a variety of research aspects, which may be conducted in upcoming years.

Fig. 3 indicates the year wise land use change situations observed since past year of 2007 to present 2015 in the study area. The slope of line directs different conditions of land use change occurred in percentage as prescribed in Table 2.

The changes in land use percentage are estimated in different years and future conversion of land for vertical development as elaborated in Table 2. Linear regression

TABLE 1. YEARLY CODE AND LAND USE CHANGE PARAMETERS FOR LINEAR REGRESSION MODEL

\begin{tabular}{|c|c|c|}
\hline No. & \multicolumn{2}{|c|}{ Variables } \\
\hline & $\mathrm{X}$ (Yearly Code) & Y (Land Use Change \%) \\
\hline 01 & $2007(\mathrm{x}=0)$ & 0.86 \\
\hline 02 & $2010(\mathrm{x}=3)$ & 1.58 \\
\hline 03 & $2012(\mathrm{x}=5)$ & 2.48 \\
\hline 04 & $2015(\mathrm{x}=8)$ & 3.39 \\
\hline
\end{tabular}

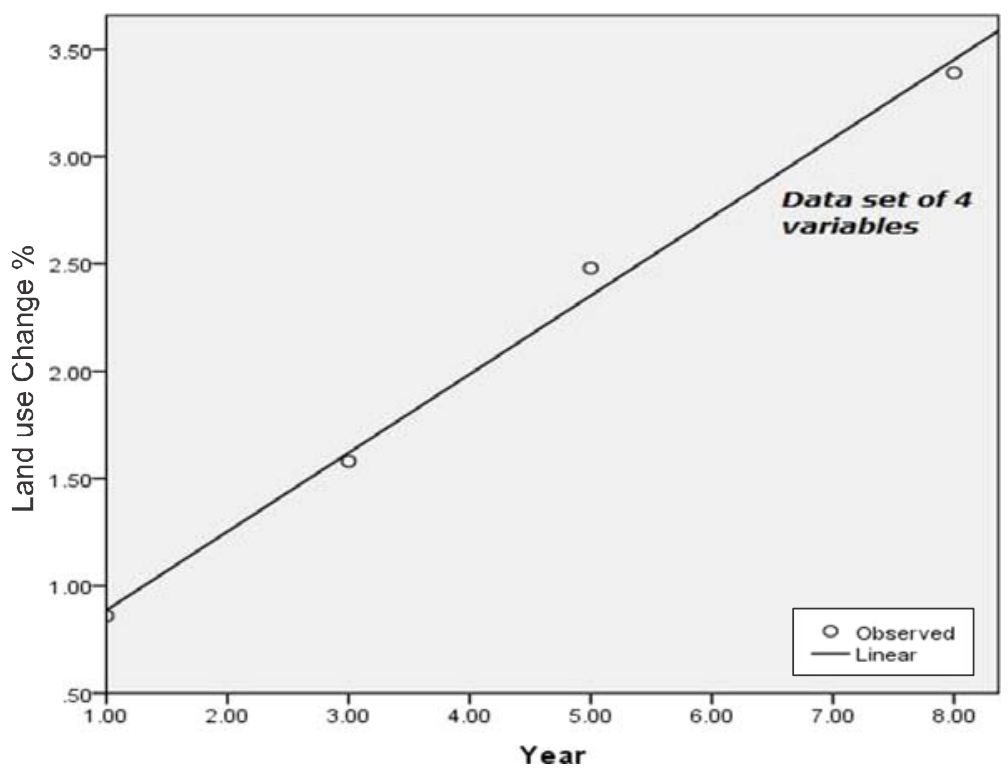

FIG. 3. LAND USE CHANGE PREDICTION MODEL (2007-2015) 
model was applied to find existing horizontal land use change in vertical development that has taken place in the study area since 2007 and predicted future differences in land use alterations. Hence, land use change in 2007 was $0.86 \%$, at present (2015) 3.39\% and it was predicted $16.25 \%$ up to 2050 year. The result shows that proposed land for horizontal development has been converting rapidly into vertical development since 2007 as indicated in Fig. 4.
The GIS (Geographical Information System) was used to determine land use change in vertical development as shown in Fig. 4. In this study, the major findings were identified by authors, which are discussed up to the boundary of Taluka Qasimabad which is spread-over 69 sq. km. Out of which, 34.34 sq. km is reserved for agriculture and 34.65 sq.km is used for physical development. Whereas, 16.63 sq.km area is developed in various land uses but still 16.92 sq.km land is nondeveloped. It reveals that physical development has

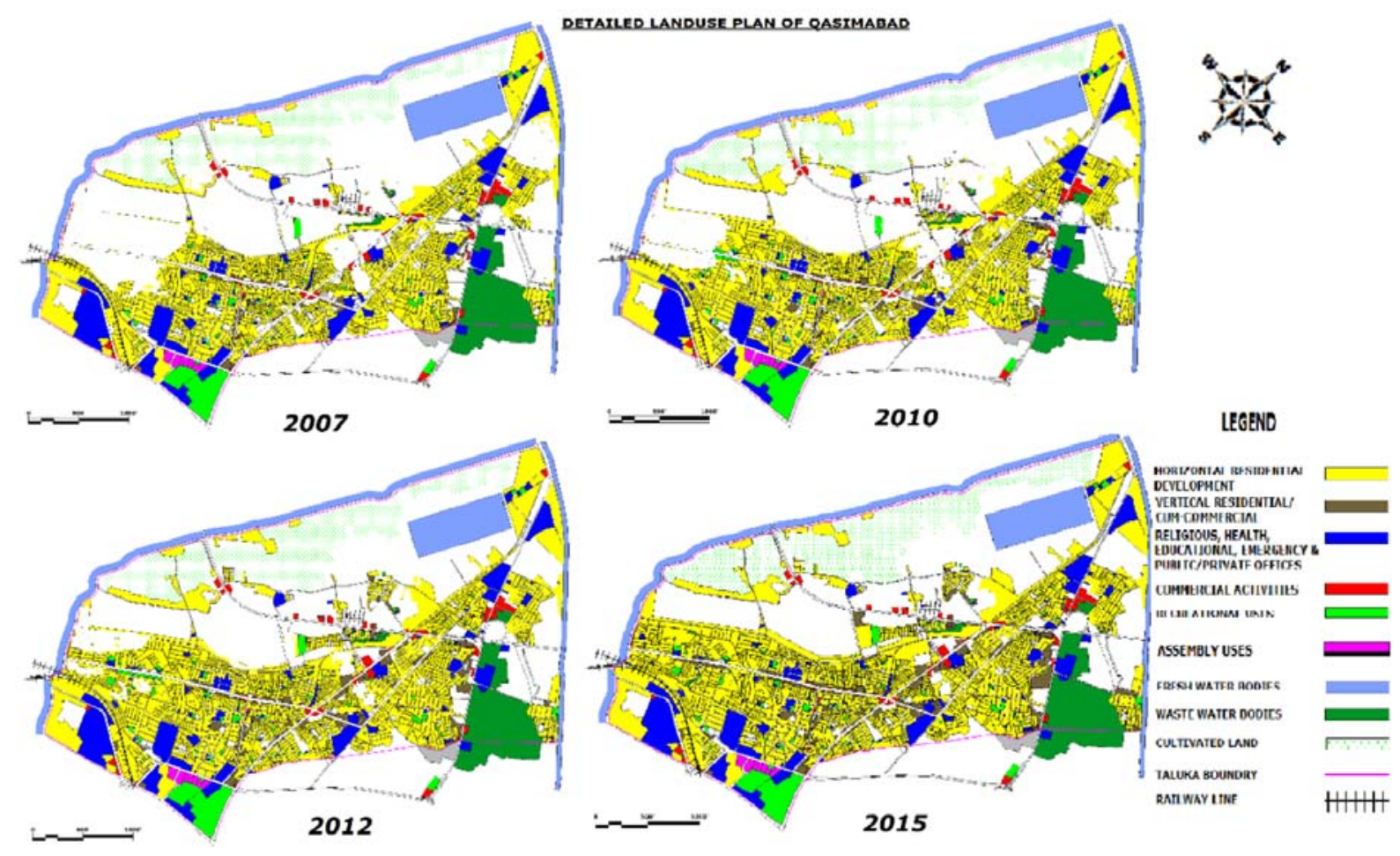

FIG. 4. GIS-BASEDLAND USE CHANGE (VERTICAL DEVELOPMENT SINCE 2007-2015)

TABLE 2. EXISTING AND PRIDICTED LAND USE CHANGE

\begin{tabular}{|c|c|c|c|c|c|}
\hline \multirow{2}{*}{ No. } & \multicolumn{2}{|c|}{ Variables } & \multicolumn{3}{|c|}{ Predicted Land Use Change (\%) } \\
\cline { 2 - 4 } & X (Year) & Y (Land use Change \%) & 2020 & 2030 & \\
\hline 01 & 2007 & 0.86 & & \multirow{2}{*}{5} \\
\hline 02 & 2010 & 1.58 & 5.2 & 16.25 \\
\hline 03 & 2012 & 2.48 & & \\
\hline 04 & 2015 & 3.39 & & \\
\hline
\end{tabular}

Mehran University Research Journal of Engineering \& Technology, Volume 37, No. 2, April, 2018 [p-ISSN: 0254-7821, e-ISSN: 2413-7219] 
been rapidly expanded irregularly. Resultant, reserved land for horizontal development is converting into vertical development. Furthermore; authors also compared detailed land use plan of 2007 formulated by Osmani Consultant with existing investigated land use plan of Taluka Qasimabad. The major difference is observed in between existing and previous detailed land use plan of Taluka Qasimabad. Mainly central Qasimabad (Naseem Nagar and Wadhu Wah) land is changed and impacted by these practices. Thus, inhabitants are facing socio-economic problems nearby their accommodations i.e. privacy, insecurity, devaluation of nearest property and orientation.
At the end, it is concluded that people are not satisfied with existing trend of urban land use planning complained by more than $70 \%$ respondents and around 70\% dwellers even are not comfortable to live in existing land use development as indicated in Figs. 5-6. The monopoly of the builders and developers negligible support by the government and political involvement is responsible to avoid proper utilization of land uses and its development control. These stakeholders are widely responsible for violating socio-economic aspects of un-planned development growth as clarified in Fig. 7.

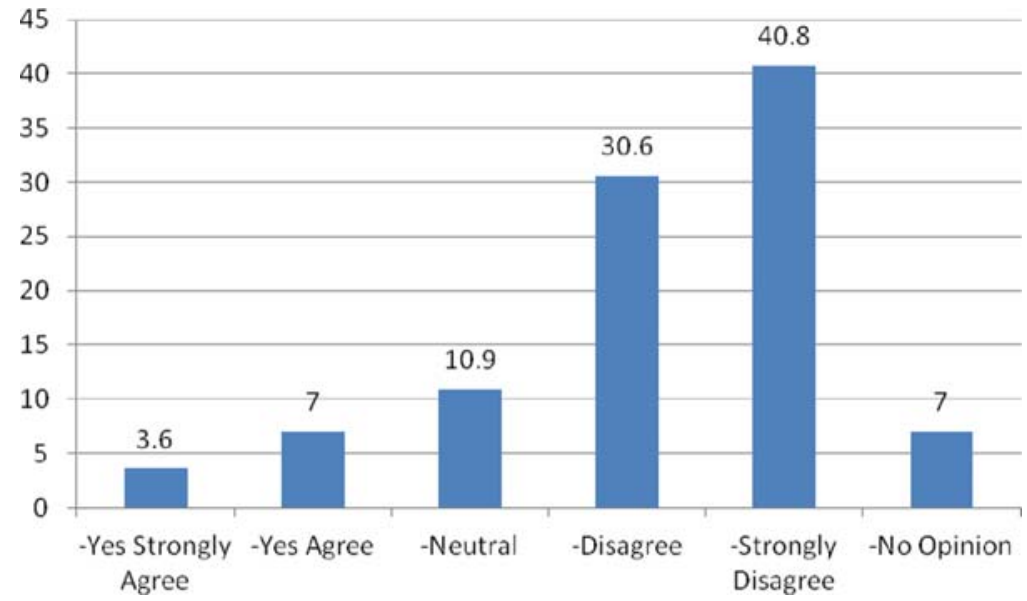

FIG. 5. RESPONDENTS SATISFACTION REGARDING EXISTING PRACTICES OF LAND USES AND ITS DEVELOPMENT OF QASIMABAD

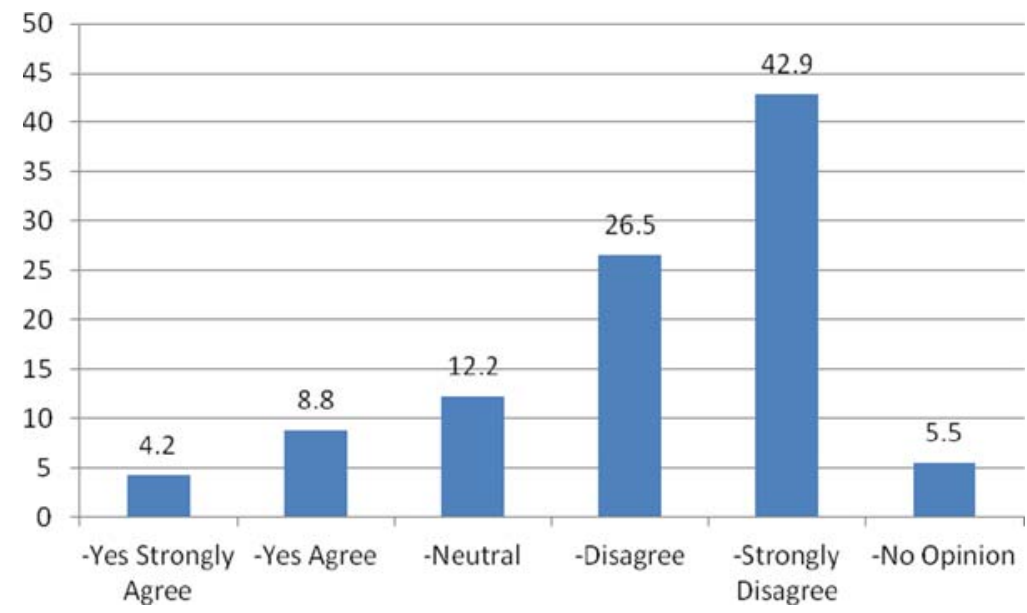

FIG. 6. RESPONDENTS VIEWS ABOUT COMFORTABLE TO LIVE IN EXISTING LAND USE PATTERNS OF QASIMABAD 


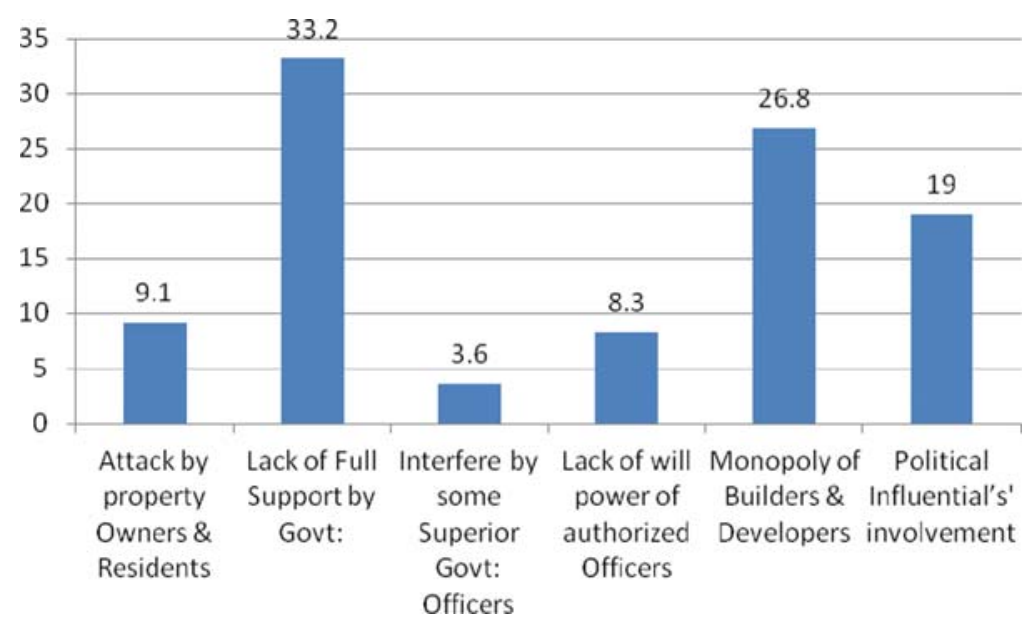

FIG. 7. RESPONSIBLE MAKING PROBLEMS TO AVOID SMOOTH ENFORCEMENT OF LAND USE \& DEVELOPMENT CONTROL

\section{CONCLUSION}

In this study, various fundamental factors are responsible for improper land use planning mainly for vertical development. Mathematical models were used to highlight existing development impacts in the study area. LRM was applied to confirm existing trend of vertical urban land uses and its adverse impacts on socioeconomic development. It is found that rapid change of land in vertical development has been increased with the passage of time. Almost $16.25 \%$ was predicted with the help of GIS in land use change. These results validated that massive land use change can be occurred up to the 2050 year. Moreover; study revealed that the residents of the city were not satisfied with the changing instances of land use patterns. There is lack of coordination between line departments involved in planning of the city, government and non-government organizations and local people. Inter disciplinary approach with emphasizing sustainable development is required, thus yielding sustainable land use development in the study area. Besides; this study can be useful for suggesting urban land use planning mechanism to control existing as well as future urban development growth to accommodate people at their desired level.

\section{ACKNOWLEDGEMENT}

Authors thank Development Authorities and concerned officials for their assistance during investigation of existing conditions and to provide secondary information of the study area. This research was conducted by Department of City \& Regional Planning, Mehran University of Engineering \& Technology, Jamshoro, Sindh, Pakistan.

\section{REFERENCES}

[1] Matthew, L., and Jianguo, W., “A Gradient Analysis of Urban Landscape Pattern: A Case Study from the Phoenix Metropolitan Region Arizona USA”, Landscape Ecology, Volume 17, No. 4, pp. 327-339, 2002.

[2] Brandful, C.P., Erdiaw-Kwasie, M.O., and Amoateng, P., “Africa's Urbanization: Implications for Sustainable Development”, Cities, Volume 47, pp. 62-72, 2015.

[3] Bahrawar, J., Iqbal, M., and Iftikharuddin, "Urbanization Trend and Population Projections of Pakistan Using Weighted Approach”, Sarhad Journal of Agriculture, Volume 24, No. 1, 2008.

[4] Seto, K.C., and Fragkias, M., "Quantifying Spatiotemporal Patterns of Urban Land-Use Change in Four Cities of China with Time Series Landscape Metrics", Landscape Ecology, Volume 20, No. 7, pp. 871-888, 2005. 
[5] State of the World's Cities 2012/2013, Prosperity of Cities, Routledge United Nations Human Settlements Programme (UN-Habitat), 2013. 711 Third Avenue, New York, NY 10017. Website: www.unhabitat.org.

Behzadi, S., and Ali, A.A., "Introducing a Novel Model of Belief-Desire Intention Agent for Urban Land Use Planning”, Engineering Applications of Artificial Intelligence, Volume 26, pp. 2028-2044, 2013.

Viegas, C.V., Saldanha, D.L., Bond, A.R., Jose, L.D., and Selig, P.M., "Urban Land Planning: The Role of a Master Plan in Influencing Local Temperatures”, Cities, Volume 35, pp. 1-13, 2013.

[8]

Cities Alliance, 2007, "Livable Cities: The Benefits of Urban Environmental Planning”, Washington DC,http:/ /www.citiesalliance.org/, Accessed on November $2^{\text {nd }} 2014$.
Issahaka, F., ndJaco, K., “A Review of Spatial Planning in Ghana's Socio-Economic Development Trajectory: A Sustainable DevelopmentPerspective”, Land Use Policy, Volume 47, pp. 300-320, 2015.

[10] Krejcie, R.V., and Morgan, D.W., "Determining Sample Size for Research Activities”, Educational and Psychological Measurement, Volume 30, pp. 607-610, 1970.

[11] Maldonado, A.D., Ropero, R.F., Aguilera, P.A., Fernández, A., Rumía, R., and Salmerón, A., "Continuous Bayesian Networks vs. Other Methods for Regression in Environmental Modeling”, Procedia Environmental Sciences, Volume 26, pp. 70-73, 2015.

[12] Zhang, Y., Chongguang, L., Tianwei, W., Chongfa, C., and Yuze, B., "County-Level Patterns of Cropland and their Relationships with Socio-Economic Factors in Northwestern China”, Agriculture, Ecosystems and Environment, Volume 203, pp. 11-18, 2015. 